\title{
Tailor-made Tympanomastoidectomy with Cartilage Reconstruction
}

\section{Chiang-Feng Lien, MD¹; Chin-Lung Kuo, MD, PhD ${ }^{1,2 *}$}

${ }^{1}$ Department of Otolaryngology-Head and Neck Surgery, Taipei Veterans General Hospital, Taipei, Taiwan

${ }^{2}$ Department of Otolaryngology, Taoyuan Armed Forces General Hospital, Taoyuan, Taiwan

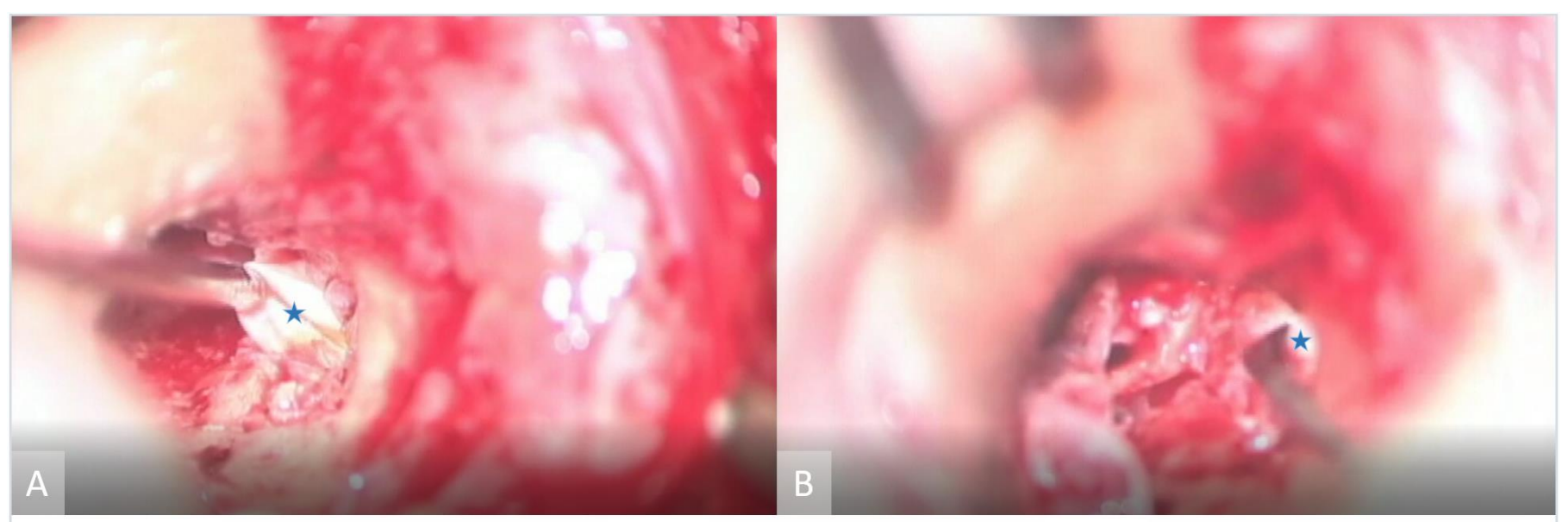

Axial view

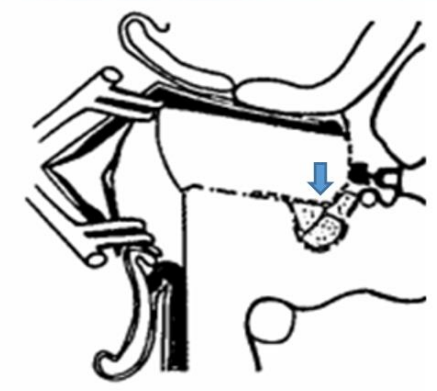

C

$$
\text { Atticotomy }
$$

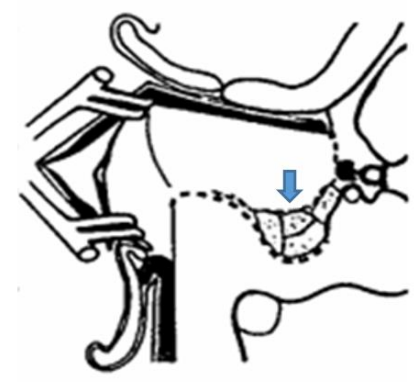

Attico-antrectomy

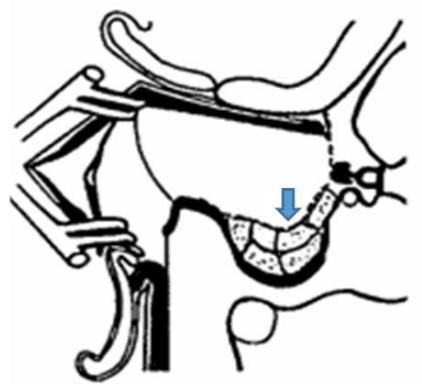

Attico-antro-mastoidectomy

S ince 1986, Dr. Lien has performed a functional surgery for cholesteatoma, tailor-made tympanomastoidectomy with cartilage reconstruction (TTCR, Video). This technique emphasizes the importance of preserving uninvolved, functional mastoid air cells, and anatomical reconstruction with cartilage, which may facilitate mastoid aeration and avoid cavity problems. The surgical technique employed was one-stage TTCR via an anterior approach. An endaural incision was made to expose the external auditory canal (EAC) and temporalis fascia. The fascia was harvested as a graft. After elevation of the tympanomeatal flap from the posterior canal wall, the EAC was enlarged and the scutum was removed, giving direct access to the cholesteatoma (asterisk in Panel A). Retrograde mastoidectomy was applied to remove the cholesteatoma, which extended along the route of involvement, thus creating an atticotomy, attico-antrectomy or attico-antro-mastoidectomy open cavity (Panel C). Conchal cartilage was harvested to reconstruct the attic and/or posterior canal wall and maintain the EAC anatomy (asterisk in Panel B and arrows in Panel C), avoiding postoperative cavity problems. Tympanoplasty was then performed to restore hearing.

DOI: 10.24983/scitemed.paciv.2017.00016

*Correspondence: Chin-Lung Kuo, MD, PhD; Department of Otolaryngology, Taoyuan Armed Forces General Hospital, Taoyuan, Taiwan.

E-mail: drkuochinlung@gmail.com

Received: June 1, 2017; Accepted: June 2, 2017; Published: June 3, 2017

Preprint Archives of Clinical Images \& Videos. 2017;1(2):4

DOI: 10.24983/scitemed.paciv.2017.00016

Copyright (C) 2017 The Author(s). This is an open-access article distributed under the terms of the Creative Commons Attribution 4.0 International License (CC-BY).

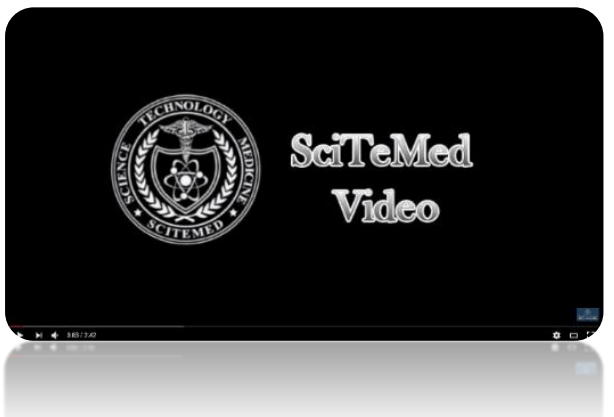

